\title{
A UWB Band-Pass Antenna with Triple-Notched Band Using Common Direction Rectangular Complementary Split-Ring Resonators
}

\author{
Bo Yan, Di Jiang, Ruimin Xu, and Yuehang Xu \\ School of Electronic Engineering, University of Electronic Science and Technology of China, Chengdu 611731, China \\ Correspondence should be addressed to Di Jiang; merryjiangdi@163.com
}

Received 3 June 2013; Accepted 10 July 2013

Academic Editor: Guo Qing Luo

Copyright (c) 2013 Bo Yan et al. This is an open access article distributed under the Creative Commons Attribution License, which permits unrestricted use, distribution, and reproduction in any medium, provided the original work is properly cited.

A novel ultrawideband (UWB) antenna which has a triple-band notch function is presented. The proposed antenna can block interfering signals from C-band satellite communication systems, IEEE802.11a, and HIPERLAN/2 WLAN systems for example. The antenna is excited by using novel common direction rectangular complementary split-ring resonators (CSRR) fabricated on radiating patch of the dielectric substrate with coplanar waveguide (CPW) feed strip line. The voltage standing wave ratio (VSWR) of the proposed antenna is less than 2.0 in the frequency band from 2.8 to $12 \mathrm{GHz}$, while showing a very sharp bandrejection performance at $3.9 \mathrm{GHz}, 5.2 \mathrm{GHz}$, and $5.9 \mathrm{GHz}$. The measurement results show that the proposed antenna provides good omnidirectional field pattern over its whole frequency band excluding the rejected band, which is suitable for UWB applications.

\section{Introduction}

Commercial ultrawideband (UWB) systems require small low-cost antennas with omnidirectional radiation pattern and large bandwidth. It is a well-known fact that planar monopole antennas present really appealing physical features, such as simple structure, small size, and low cost. Due to all these interesting characteristics, planar monopoles are extremely attractive to be used in emerging UWB applications, and growing research activity is being focused on them. However, their size and bandwidth should be improved, and also their shapes should have simple structure for easy manufacturing [1]. Recently, many techniques have been examined to enhance the antenna bandwidth including the truncated ground plane with the use of an L-shaped notch in the lower corner and an inverted T-shaped notch in the middle [2]. In this proposed antenna, two new slots are used in the ground plane; by using these notches, an additional two resonances are excited, and hence the bandwidth is increased [3]. For UWB systems, the frequency range is between 3.1 and $10.6 \mathrm{GHz}$, and hence it can interfere with the existing wireless communication system such as wireless local area network (WLAN) $(5.15-5.35 \mathrm{GHz}, 5.725-5.825 \mathrm{GHz})$, so the UWB antenna with a notch-band performance is required [4]. To generate the band-notch frequency, a planar monopole antenna with an inverted U-slot, small strip bar, and two Ushaped slots in the patch is proposed [5]. In this paper, a base swallow-shaped-patch (SSP) antenna is proposed to cover the UWB range, which has a UWB operating bandwidth with a tunable triple-notched frequency at $3.9 \mathrm{GHz}, 5.2 \mathrm{GHz}$ and $5.9 \mathrm{GHz}$. The band-notched operation is achieved by embedding codirectional modified rectangle CSRR slots on radiated patch. The CSRR is under investigation by researchers to implement left-hand materials the codirectional rectangle complementary split-ring resonator (CSRR) is promising for UWB antennas to ensure multiple notched bands [6]. Both triple-band-notched characteristics and compact size are achieved. The antenna has promising features, including good impedance matching performance over the whole operating frequency band, stable radiation patterns, and flexible frequency-notched function. 


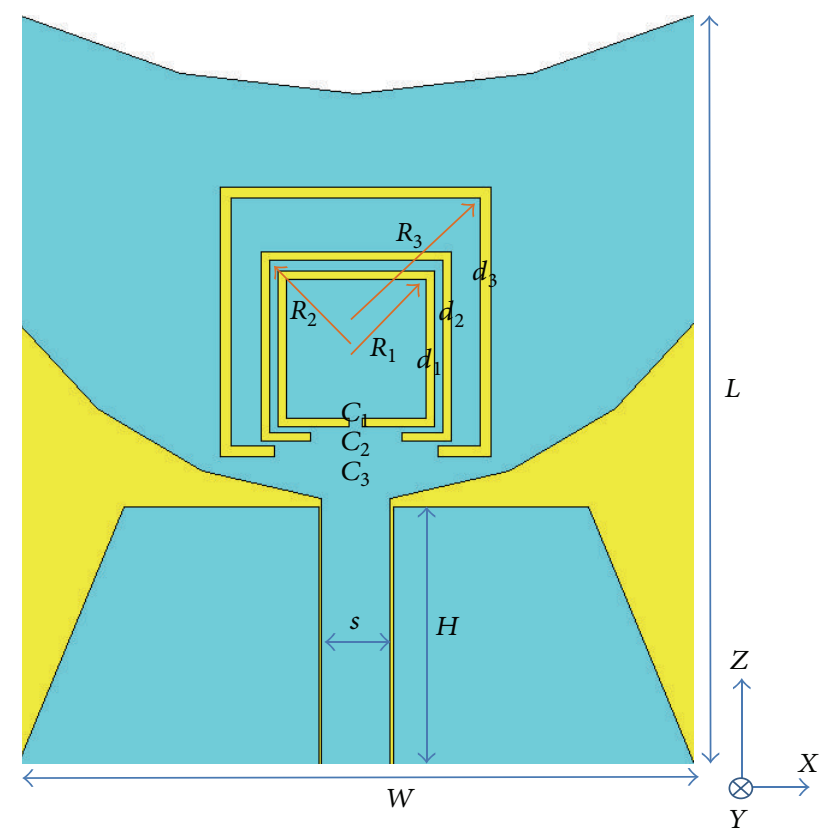

FIgURE 1: Geometry of antenna, with dimensions $R_{1}=3.75 \mathrm{~mm}$, $R_{2}=4.61 \mathrm{~mm}, R_{3}=6.6 \mathrm{~mm}, C_{1}=0.5 \mathrm{~mm}, C_{2}=3.35 \mathrm{~mm}, C_{3}=$ $6 \mathrm{~mm}, d_{1}=0.3 \mathrm{~mm}, d_{2}=0.3 \mathrm{~mm}, d_{3}=0.4 \mathrm{~mm}, s=2.5 \mathrm{~mm}, H=$ $9.8 \mathrm{~mm}, W=25 \mathrm{~mm}$, and $L=27.9 \mathrm{~mm}$.

\section{Antenna Design}

Figure 1 shows the configuration of the proposed antenna. It is printed on an $0.508 \mathrm{~mm}$ thick RT5880 substrate with the relative permittivity $\varepsilon r=2.2$ and loss tangent $\tan \delta=0.0009$. The CPW-fed antenna is composed of a swallow-shaped radiator on the same layer and a trapezoidal ground plane. In designing the antenna, the lowest operating frequency depends on the largest triangle complementary split-ring resonators [7]. Compared with the symmetrical antennas, the radiator is located at an offset distance from the center of the structure to feature an asymmetrical shape, which has the advantage of easing the requirement on the space for placing band-rejected elements. The band-notched performance can be obtained by adding three-quarter-wavelength band-rejected elements. The problem of interference with C-band (3.7-4.2 GHz) satellite communication systems, lower WLAN band (5.15$5.35 \mathrm{GHz})$, and upper WLAN band $(5.725-5.825 \mathrm{GHz})$ can be settled by rectangle ring3 $\left(R_{3}\right)$, rectangle ring $2\left(R_{2}\right)$, and rectangle ring1 $\left(R_{1}\right)$, respectively. It is found that, by tuning the length of the codirectional rectangular complementary split-ring resonators ring to be approximately a quarter wavelength at the desired rejected frequency, an additional resonance can be introduced to the antenna response, causing the antenna to be nonresponsive at that frequency. The bandnotched performance at $5.15 \mathrm{GHz}-5.35 \mathrm{GHz}$ and $5.725 \mathrm{GHz}-$ $5.825 \mathrm{GHz}$ can be improved by allocating a combination of rectangle ring2 and rectangle ring1. It is also worthwhile mentioning that, when considering the arrangement of the bandrejected elements, the mutual coupling can be avoided at the notched frequencies by placing rectangle ring3, rectangle ring2, and rectangle ring1, since the lower WLAN band and the upper WLAN band are close to each other [8]. As a result, the rejected frequency can be easily tuned by changing each rectangle ring independently [9].

Figure 2 shows the current distributions at three centernotched bands. The dimensions of three co-directional rectangle complementary SRRs are corresponding to three notched bands. When the antenna is working at the center of lower-notched band near 3.9 GHz, the outer complementary SRR behaves as a separator in Figure 2(a), which almost has no relation to the other band notches [10]. Similarly, the middle complementary SRR operates as a second separator for the center of middle-notched band near $5.2 \mathrm{GHz}$ in Figure 2(b). From Figure 2(c), the upper-notched band near $5.9 \mathrm{GHz}$ is ensured by the inner complementary SRR [11]. Additionally, as a certain current crowded on the ground plane near the CPW feed line would affect the antenna performance, we find that the dimension of ground plane, especially, has a significant effect on the triple-band-notche performance, as well as impedance bandwidth [12].

\section{Results and Discussion}

The proposed SSP antenna is successfully fabricated and measured, with the optimized size shown in Figure 3. Figure 4 displays the measured and simulated VSWR for the antenna [13]. It is seen that the proposed antenna exhibits three notched bands of $3.68 \mathrm{GHz}-4.20 \mathrm{GHz}, 5.05 \mathrm{GHz}-5.38 \mathrm{GHz}$, and $5.72 \mathrm{GHz}-6.08 \mathrm{GHz}$, respectively, covering C-band satellite communication systems and WLAN, while maintaining wideband performance from 2.8 to $12 \mathrm{GHz}$ for VSWR $<2$, covering the entire UWB frequency band [14]. The measured VSWR is slightly lower than the simulated result and it may be due to loss tangent $\tan \delta$ of the substrate and the tolerance in manufacturing.

Figures 5 and 6 show the simulated and measured 2D radiation patterns, respectively, at frequencies of $3.5 \mathrm{GHz}$, $5 \mathrm{GHz}$, and $7 \mathrm{GHz}$ for the proposed UWB antenna. Measurements of the radiation patterns of the prototype are carried out in an anechoic chamber [15]. It is seen that the radiation patterns in $x y$-plane ( $H$-plane) are almost omnidirectional and the radiation patterns in $y z$-plane (E-plane) are monopole alike. Clearly, the triple-notch UWB antenna has a good radiation performance when it operates at $3.5 \mathrm{GHz}$, $5 \mathrm{GHz}$, and $7 \mathrm{GHz}[16]$. By comparing with Figures 5 and 6, the measured radiation patterns show slight deterioration in copolarization and cross-polarization electric field. To some extent, this is because of the measurement environment. Particularly, the SMA feeding connector may have interference with radiation field in the test. Distortions in the $E$-plane patterns begin to occur at higher frequencies because the radiating elements are no longer small relative to those wavelengths.

Figure 7 reveals its measured peak gain and simulated realized gain versus frequency. As can be seen from Figure 7, the simulation result and measured result fit with each other well. It is observed that the antenna keeps a stable antenna 


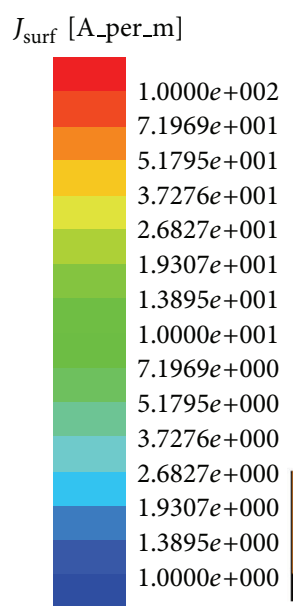

(a)

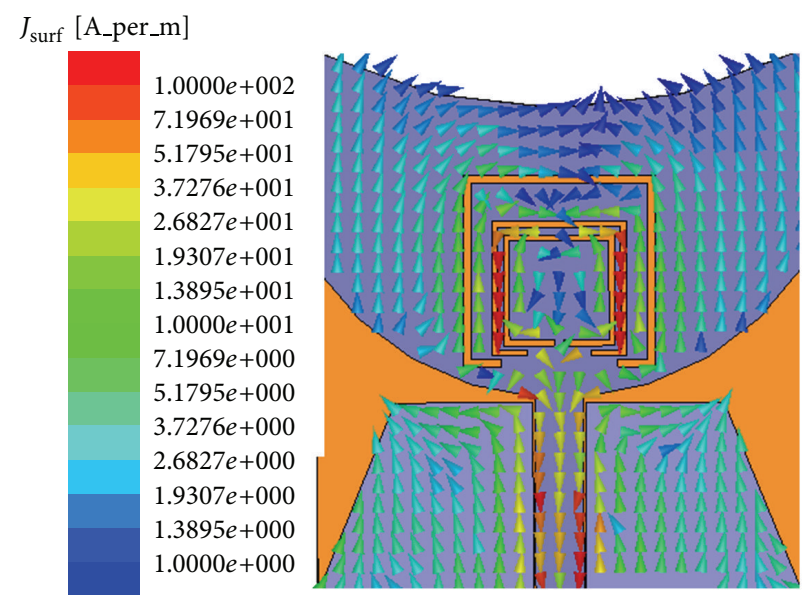

(b)

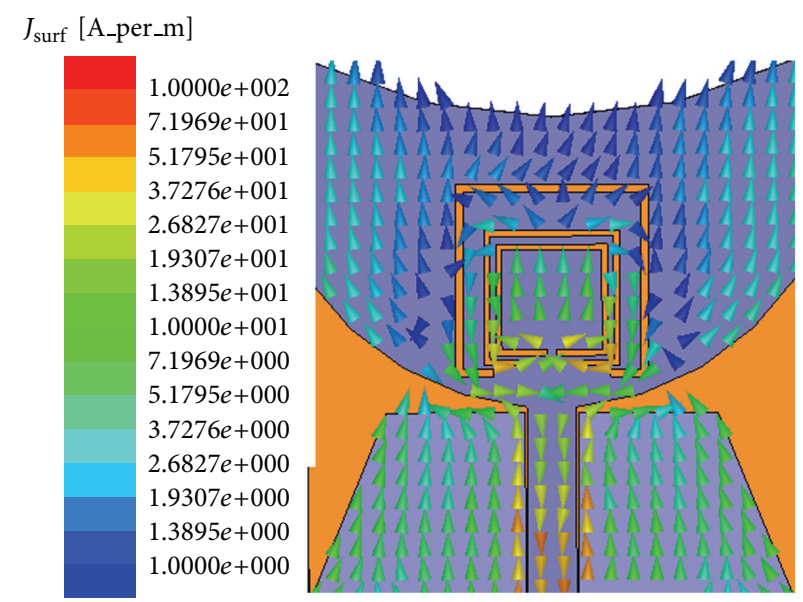

(c)

Figure 2: The current distribution at different frequencies (a) $3.9 \mathrm{GHz}$, (b) $5.2 \mathrm{GHz}$, and (c) $5.9 \mathrm{GHz}$.

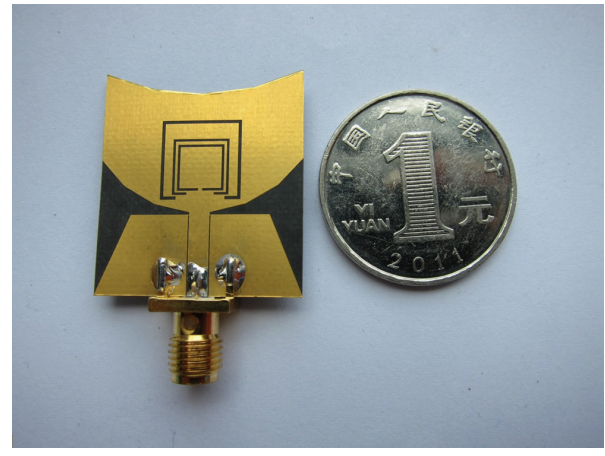

FIgURE 3: Photograph of the proposed antenna.

gain about $3-4 \mathrm{dBi}$ but decreases significantly to about $-10 \mathrm{dBi},-6.5 \mathrm{dBi}$, and $-5 \mathrm{dBi}$ at the three notched bands, which demonstrates that the antenna has great triple-bandnotched characteristics.

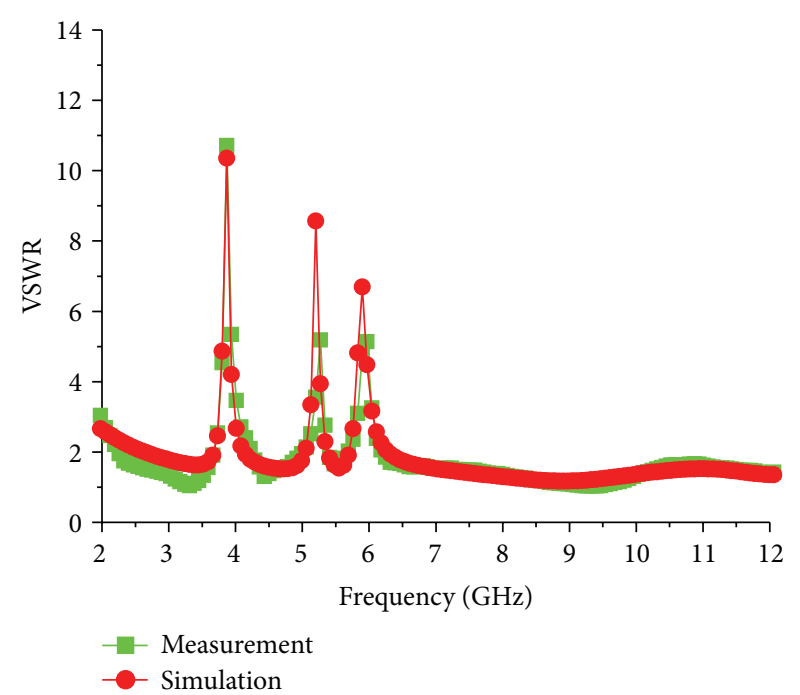

FIGURE 4: Comparison of simulated and measured VSWR of the proposed antenna. 

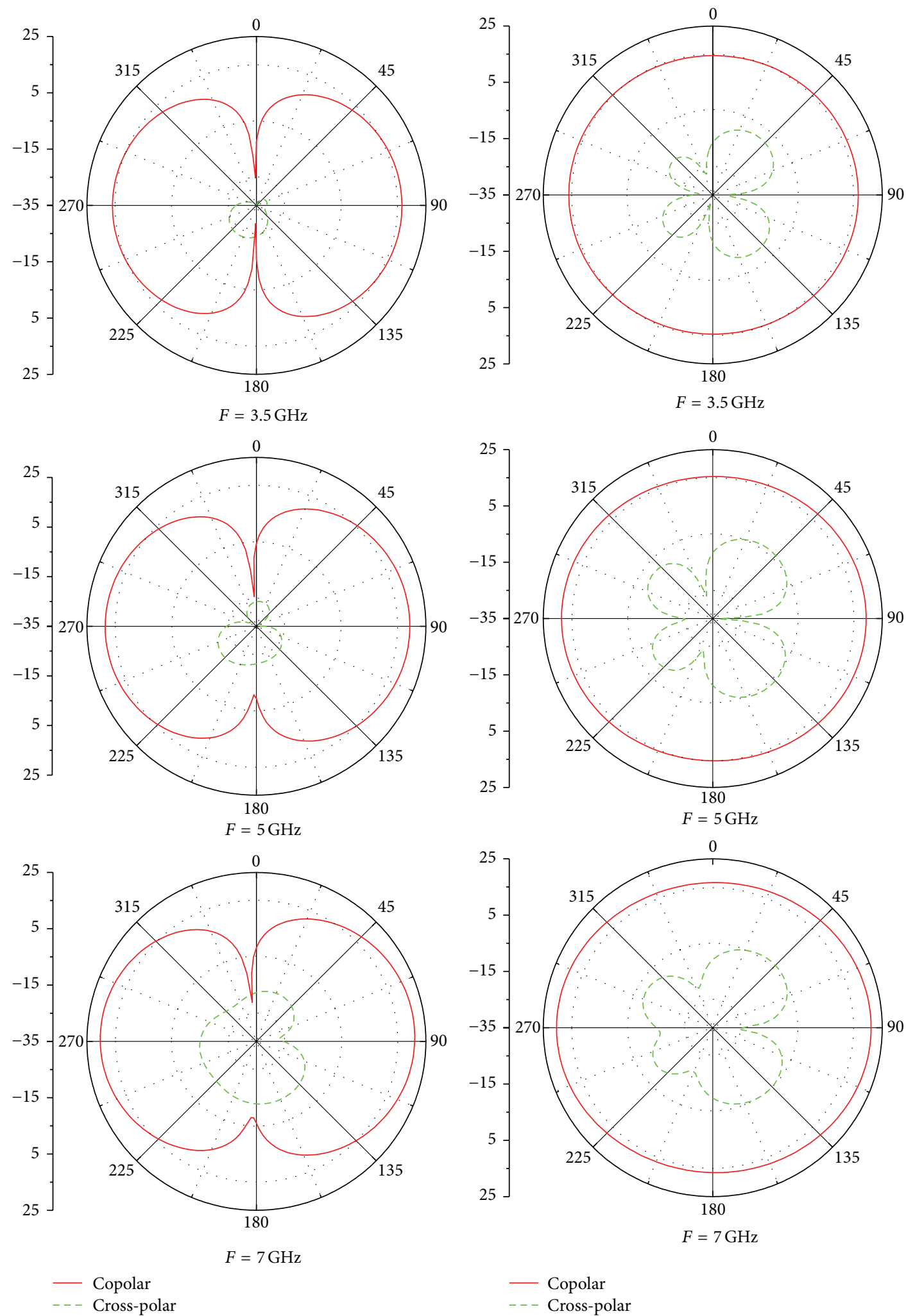

(a)

(b)

FIGURE 5: Simulated radiation patterns at (a) $y z$-plane and (b) $x y$-plane. 

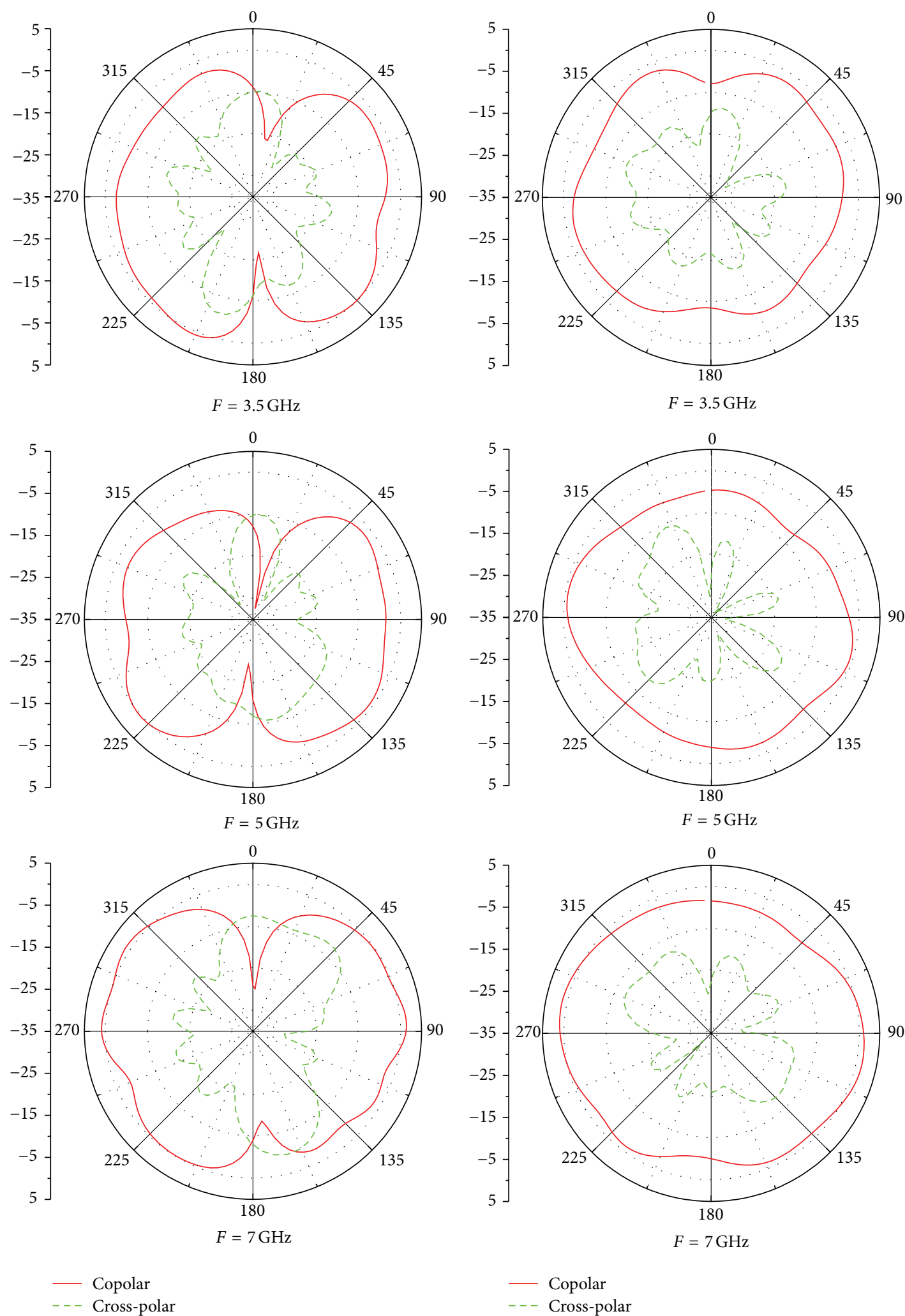

(a)

(b)

FIGURE 6: Measured radiation patterns at (a) $y z$-plane and (b) $x y$-plane. 


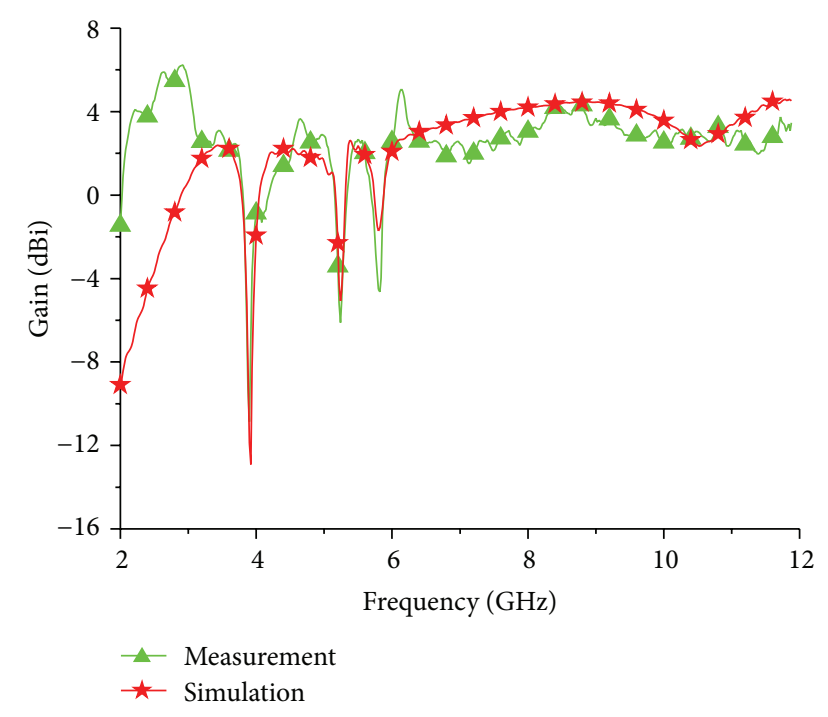

FIGURE 7: Comparison of simulated and measured gains of the proposed antenna.

\section{Conclusion}

A new printed asymmetrical UWB antenna providing multiple-band-notched function has been presented. The antenna can operate in a wide frequency range and feature improved band-notched performance. The proposed design is validated by the comparison between simulation and measurement. It can be used to avoid interference with other systems operating in the C-band satellite communication systems or WLAN bands.

\section{Acknowledgments}

This work is supported by the National Natural Science Foundation of China (Grant no. 61106115) and the Fundamental Research Funds for the Central Universities (ZYGX2011J018).

\section{References}

[1] Z. N. Chen, N. Yang, Y.-X. Guo, and M. Y. W. Chia, "An investigation into measurement of handset antennas," IEEE Transactions on Instrumentation and Measurement, vol. 54, no. 3, pp. 1100-1110, 2005.

[2] L. Liu, Y. Z. Yin, C. Jie, J. P. Xiong, and Z. Cui, "A compact printed antenna using slot-type CSRR for $5.2 \mathrm{GHz} / 5.8 \mathrm{GHz}$ band-notched UWB application," Microwave and Optical Technology Letters, vol. 50, no. 12, pp. 3239-3242, 2008.

[3] M. Naser-Moghadasi, G. R. DadashZadeh, A.-A. Kalteh, and B. S. Virdee, "Design of a novel band-notched slot patch antenna for UWB communication systems," Microwave and Optical Technology Letters, vol. 52, no. 7, pp. 1599-1603, 2010.

[4] D. Piazza, P. Mookiah, M. D’Amico, and K. R. Dandekar, "Experimental analysis of pattern and polarization reconfigurable circular patchantennas for MIMO systems," IEEE Transactions on Vehicular Technology, vol. 59, no. 5, pp. 2352-2362, 2010.
[5] S. L. Steven Yang, A. A. Kishk, and K. F. Lee, "Frequency reconfigurable U-slot microstrip patch antenna," IEEE Antennas and Wireless Propagation Letters, vol. 7, pp. 127-129, 2008.

[6] D. Jiang, Y. Xu, R. Xu, and W. Lin, "Compact dual-bandnotched UWB planar monopole antenna with modified CSRR," Electronics Letters, vol. 48, no. 20, pp. 1250-1252, 2012.

[7] S. Nikolaou, N. D. Kingsley, G. E. Ponchak, J. Papapolymerou, and M. M. Tentzeris, "UWB elliptical monopoles with a reconfigurable band notch using MEMS switches actuated without bias lines," IEEE Transactions on Antennas and Propagation, vol. 57, no. 8, pp. 2242-2251, 2009.

[8] S. Nikolaou, R. Bairavasubramanian, C. Lugo Jr. et al., "Pattern and frequency reconfigurable annular slot antenna using pin diodes," IEEE Transactions on Antennas and Propagation, vol. 54, no. 2, pp. 439-448, 2006.

[9] Ansoft High Frequency Structure Simulation (HFSS).ver. 10 AnsoftCorp, 2005.

[10] F. Falcone, T. Lopetegi, M. A. G. Laso et al., "Babinet principle applied to the design of metasurfaces and metamaterials," Physical Review Letters, vol. 93, no. 19, Article ID 197401, 2004.

[11] J. Ding, Z. Lin, Z. Ying, and S. He, "A compact ultra-wideband slot antenna with multiple notch frequency bands," Microwave and Optical Technology Letters, vol. 49, no. 12, pp. 3056-3060, 2007.

[12] Y. D. Dong, W. Hong, Z. Q. Kuai et al., "Development of ultrawideband antenna with multiple band-notched characteristics using half mode substrate integrated waveguide cavity technology," IEEE Transactions on Antennas and Propagation, vol. 56, no. 9, pp. 2894-2902, 2008.

[13] K. S. Ryu and A. A. Kishk, "UWB antenna with single or dual band-notches for lower WLAN band and upper WLAN band," IEEE Transactions on Antennas and Propagation, vol. 57, no. 12, pp. 3942-3950, 2009.

[14] X. N. Low, Z. N. Chen, and T. S. P. See, "A UWB dipole antenna with enhanced impedance and gain performance," IEEE Transactions on Antennas and Propagation, vol. 57, no. 10, pp. 29592966, 2009.

[15] M.-C. Tang, S. Xiao, T. Deng et al., "Compact UWB antenna with multiple band-notches for WiMAX and WLAN," IEEE Transactions on Antennas and Propagation, vol. 59, no. 4, pp. 1372-1376, 2011.

[16] A. Nouri and G. R. Dadashzadeh, "A compact UWB bandnotched printed monopole antenna with defected ground structure," IEEE Antennas and Wireless Propagation Letters, vol. 10, pp. 1178-1181, 2011. 

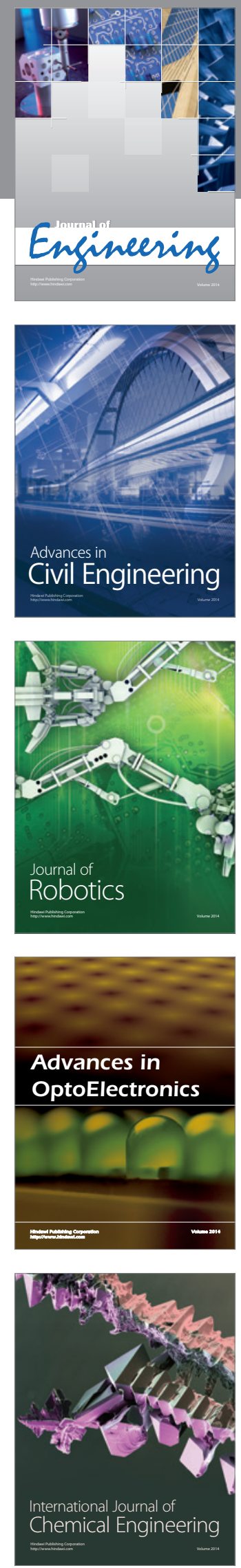

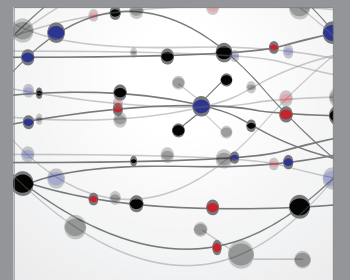

The Scientific World Journal
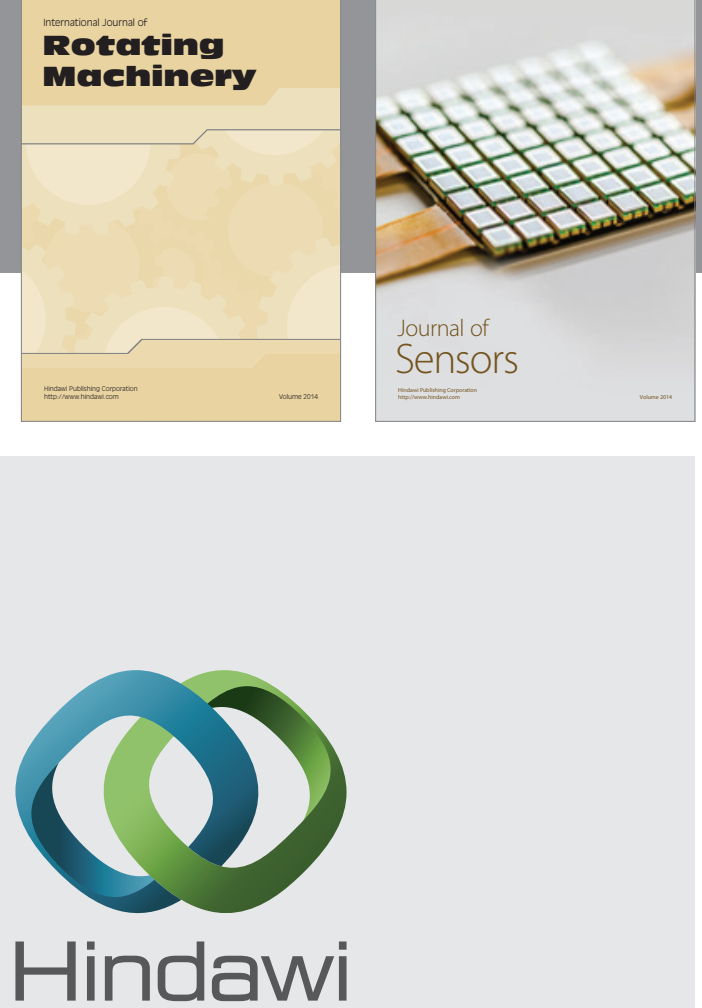

Submit your manuscripts at http://www.hindawi.com
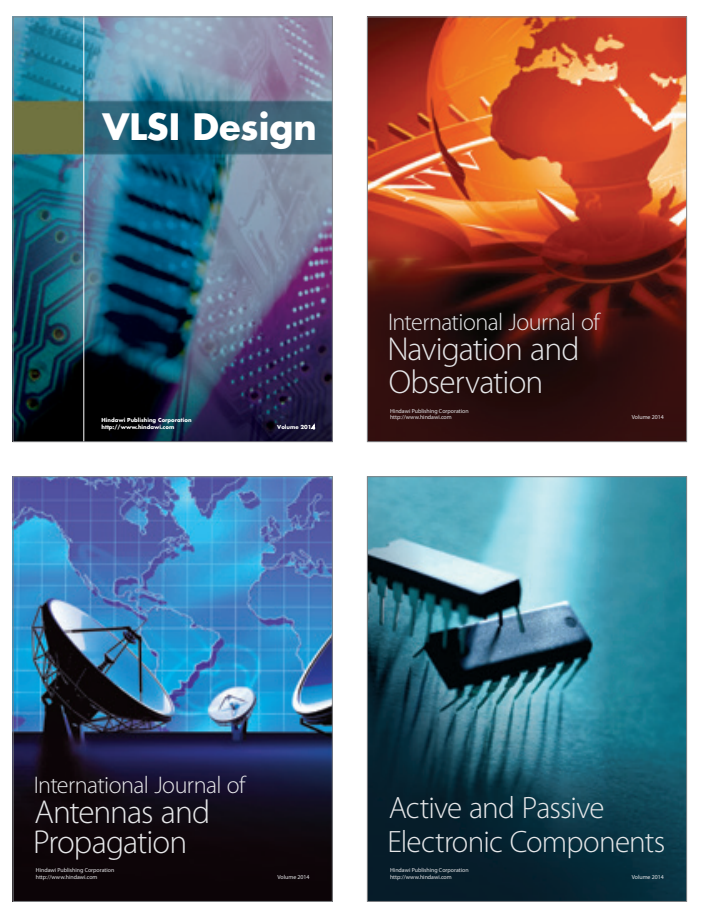
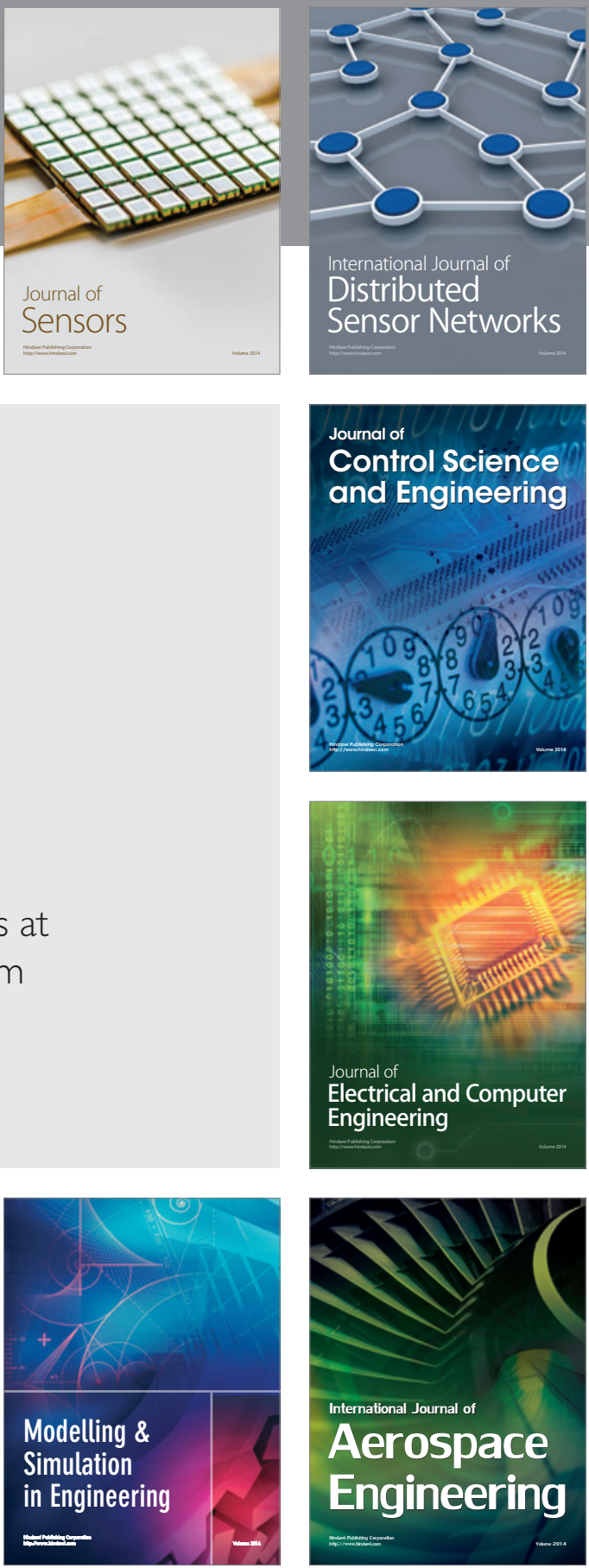

Journal of

Control Science

and Engineering
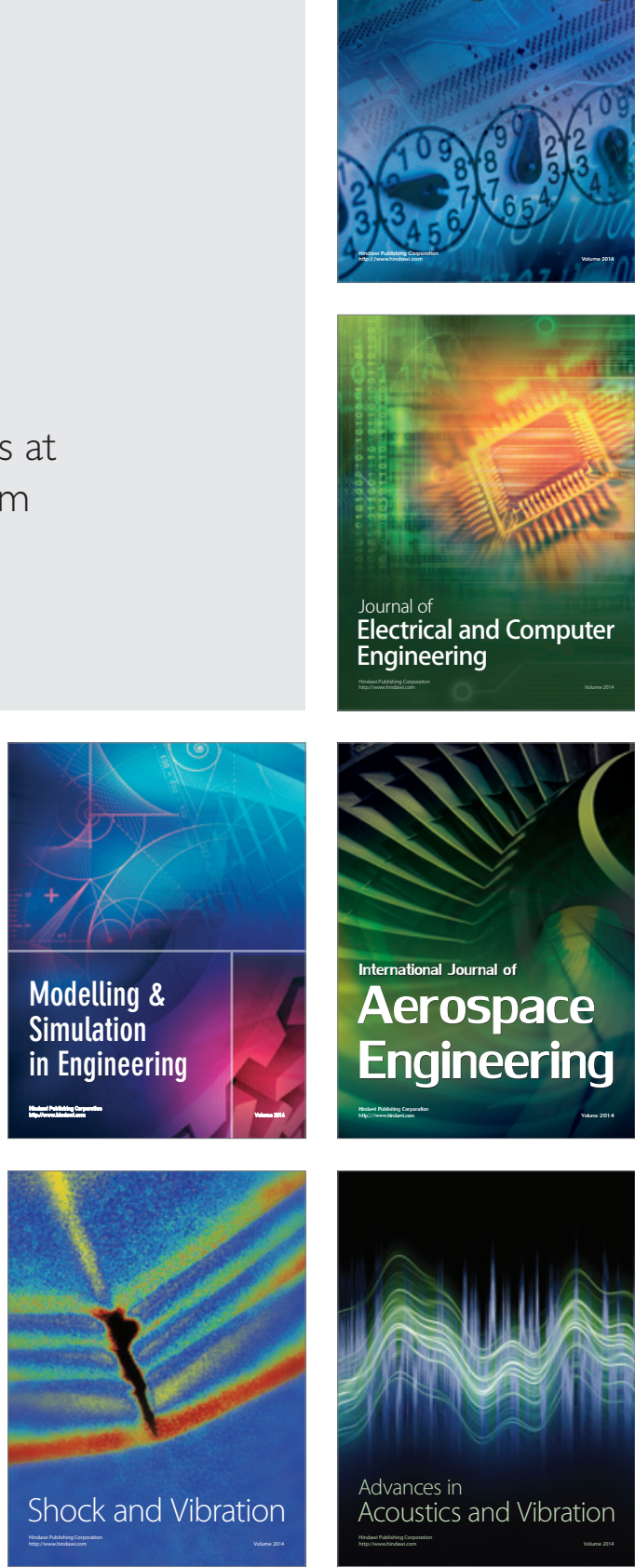